\title{
Short-term increase in prevalence of nasopharyngeal carriage of macrolide- resistant Staphylococcus aureus following mass drug administration with azithromycin for trachoma control
}

Ebrima Bojang ${ }^{1}$, James Jafali', Vincent Perreten ${ }^{2}$, John Hart ${ }^{3}$, Emma M. Harding-Esch ${ }^{3}$, Ansumana Sillah ${ }^{4}$,

David C. W. Mabey ${ }^{3}$, Martin J. Holland ${ }^{3}$, Robin L. Bailey ${ }^{3}$, Anna Roca ${ }^{1,5}$ and Sarah E. Burr ${ }^{1,3^{*}}$

\begin{abstract}
Background: Mass drug administration (MDA) with azithromycin is a corner-stone of trachoma control however it may drive the emergence of antimicrobial resistance. In a cluster-randomized trial (Clinical trial gov NCT00792922), we compared the reduction in the prevalence of active trachoma in communities that received three annual rounds of MDA to that in communities that received a single treatment round. We used the framework of this trial to carry out an opportunistic study to investigate if the increased rounds of treatment resulted in increased prevalence of nasopharyngeal carriage of macrolide-resistant Staphylococcus aureus. Three cross-sectional surveys were conducted in two villages receiving three annual rounds of MDA ( $3 \times$ treatment arm). Surveys were conducted immediately before the third round of MDA (CSS-1) and at one (CSS-2) and six (CSS-3) months after MDA. The final survey also included six villages that had received only one round of MDA 30 months previously ( $1 \times$ treatment arm).

Results: In the $3 \times$ treatment arm, a short-term increase in prevalence of $S$. aureus carriage was seen following MDA from $24.6 \%$ at CSS-1 to $38.6 \%$ at CSS-2 ( $p<0.001)$. Prevalence fell to $8.8 \%$ at CSS-3 $(p<0.001)$. A transient increase was also seen in prevalence of carriage of azithromycin resistant $\left(\mathrm{Azm}^{\mathrm{R}}\right)$ strains from $8.9 \%$ at CSS-1 to $34.1 \%(p<0.001)$ in CSS-2 and down to 7.3\% ( $p=0.417)$ in CSS-3. A similar trend was observed for prevalence of carriage of macrolideinducible-clindamycin resistant $\left(\mathrm{iMLS}_{\mathrm{B}}\right)$ strains. In CSS-3, prevalence of carriage of resistant strains was higher in the $3 \times$ treatment arm than in the $1 \times$ treatment $\left(\mathrm{Azm}^{\mathrm{R}} 7.3 \%\right.$ vs. $1.6 \%, p=0.010 ; \mathrm{iMLS}_{\mathrm{B}} 5.8 \%$ vs. $\left.0.8 \%, p<0.001\right)$. Macrolide resistance was attributed to the presence of $\mathrm{msr}$ and erm genes.
\end{abstract}

Conclusions: Three annual rounds of MDA with azithromycin were associated with a short-term increase in both the prevalence of nasopharyngeal carriage of $S$. aureus and prevalence of carriage of $A z m^{R}$ and $i M L S_{B} S$. aureus.

Trial registration: This study was ancillary to the Partnership for the Rapid Elimination of Trachoma, ClinicalTrials.gov NCT00792922, registration date November 17, 2008.

Keywords: Trachoma, Azithromycin, Mass drug administration, Staphylococcus aureus carriage, Macrolide resistance, $\mathrm{iMLS}_{\mathrm{B}}$, The Gambia, West Africa

\footnotetext{
* Correspondence: Sarah.Burr@lshtm.ac.uk

'Disease Control and Elimination Theme, Medical Research Council Unit, The

Gambia, Fajara, Banjul, The Gambia

${ }^{3}$ Department of Clinical Research, London School of Hygiene and Tropical

Medicine, London WC1E 7HT, UK

Full list of author information is available at the end of the article
} 


\section{Background}

Trachoma, caused by ocular infection with the intracellular bacterium Chlamydia trachomatis, is the leading infectious cause of blindness worldwide. Mass drug administration (MDA) with the broad-spectrum antibiotic azithromycin is an important part of the World Health Organization's integrated strategy for trachoma control $[1,2]$. This treatment serves to decrease the reservoir of infection, thereby reducing transmission.

There has been increased interest in MDA with azithromycin following the publication of studies conducted in Ethiopia suggesting treatment is associated with a significant reduction in childhood mortality [3, 4]. Calls to expand azithromycin distribution beyond trachoma-endemic countries [5] and a large-scale clinical trial to evaluate the effect of treatment on mortality that is underway in three African countries [6] bring a greater need to document unintended effects of treatment, including the emergence of antimicrobial resistance, which is a global public health concern.

There is, as yet, no evidence to suggest MDA of azithromycin at the community-level leads to increased azithromycin resistance in ocular Chlamydia trachomatis infection [7-9]. However, there are data supporting an association of MDA with the emergence of macrolide-resistant Streptococcus pneumoniae isolated from the nasopahrnyx, at least in some settings. While studies carried out in Tanzania, Nepal and The Gambia have shown no evidence of such resistance following a single treatment round [10-12], other studies in Tanzania, Nepal and Australia suggest resistance does emerge after just one or two annual rounds of mass treatment [13-15]. Further studies in Ethiopia have documented increased macrolide resistant pneumococci isolated following four rounds of MDA given at 3 month intervals [16] and following six biannual rounds over a period of 3 years [17]. To date, little work has been carried out to assess the effect of MDA with azithromycin on other bacterial pathogens.

Staphylococcus aureus colonization is a risk factor for many conditions ranging from skin and soft tissue infections in children to invasive disease such as neonatal sepsis, bacteraemia and endocarditis [18-22]. In West Africa, it has been shown to be a significant cause of invasive disease in young children [23, 24]. However, the potential effect of azithromycin MDA on prevalence of carriage of $S$. aureus including macrolide resistant strains has not yet been explored. In the present study, we used the framework of a clinical trial, which compared the prevalence of active trachoma in Gambian communities that received three annual rounds of azithromycin MDA to that of communities that received a single MDA round [25, 26] to explore whether three rounds of MDA drove increased nasopharyngeal carriage of azithromycin resistant $S$. aureus.

\section{Methods}

\section{Study design}

The Partnership for the Rapid Elimination of Trachoma (PRET) study (ClinicalTrials.gov NCT00792922) was a cluster randomized controlled trial, the design of which has been described elsewhere [25, 26]. Briefly, the study compared the effectiveness of three versus one round of azithromycin MDA in reducing the prevalence of active trachoma and ocular C. trachomatis infection. Treatment was a single oral dose of $20 \mathrm{mg}$ azithromycin per $\mathrm{kg}$ to a maximum of $1 \mathrm{~g}$ and height was used as a proxy for weight. A pneumococcal carriage study was nested within PRET [12] and was carried out in eight villages that were a part of the larger trial. This included two villages that had been randomized, by the underlying PRET trial, to three annual rounds of MDA $(3 \times$ treatment arm) and six villages that received a single treatment round $(1 \times$ treatment arm) (Figs. 1 and 2). All villages had also participated in a trial of pneumococcal conjugate vaccine and were part of that study's control arm, where children under 5 years of age received PCV-7 [27].

Three cross-sectional surveys (CSS) were conducted in the $3 \times$ treatment arm: CSS-1, 1 month prior to the third round of MDA; CSS-2, 1 month following the third round of MDA; and CSS-3, 6 months following the third round (Figs. 1 and 2). CSS-3 also included villages in the $1 \times$ treatment arm that had received one round of MDA 30 months previously (Figs. 1 and 2).

Census data were gathered in the week before CSS-1. All censused children under the age of 15 years and present at the time of sampling were invited to participate. For individuals 15 years of age or older, 150 individuals were randomly selected at each of CSS-1 and CSS-2 and in both treatment arms in CSS-3. Random selection was independent at each CSS.

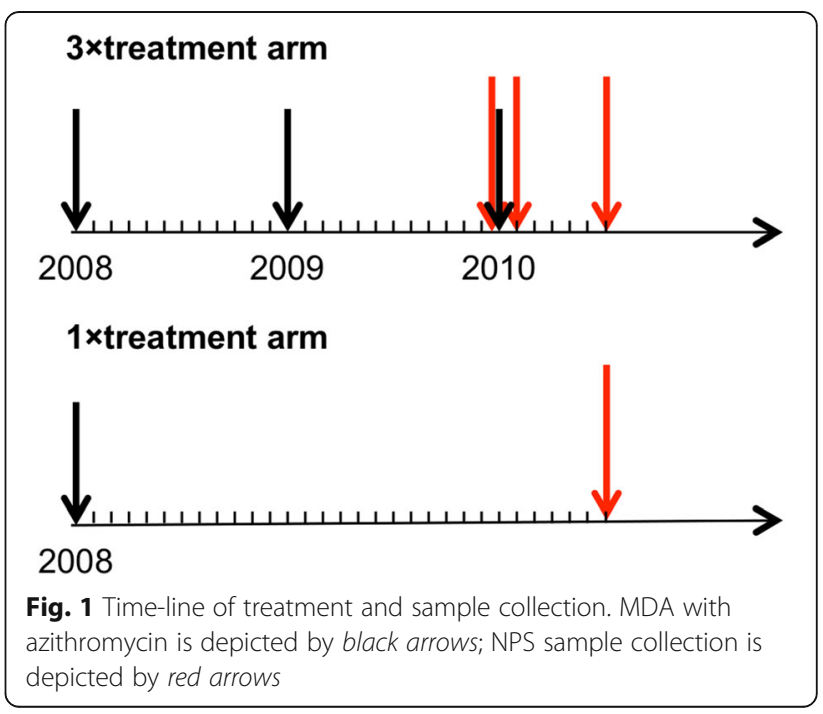




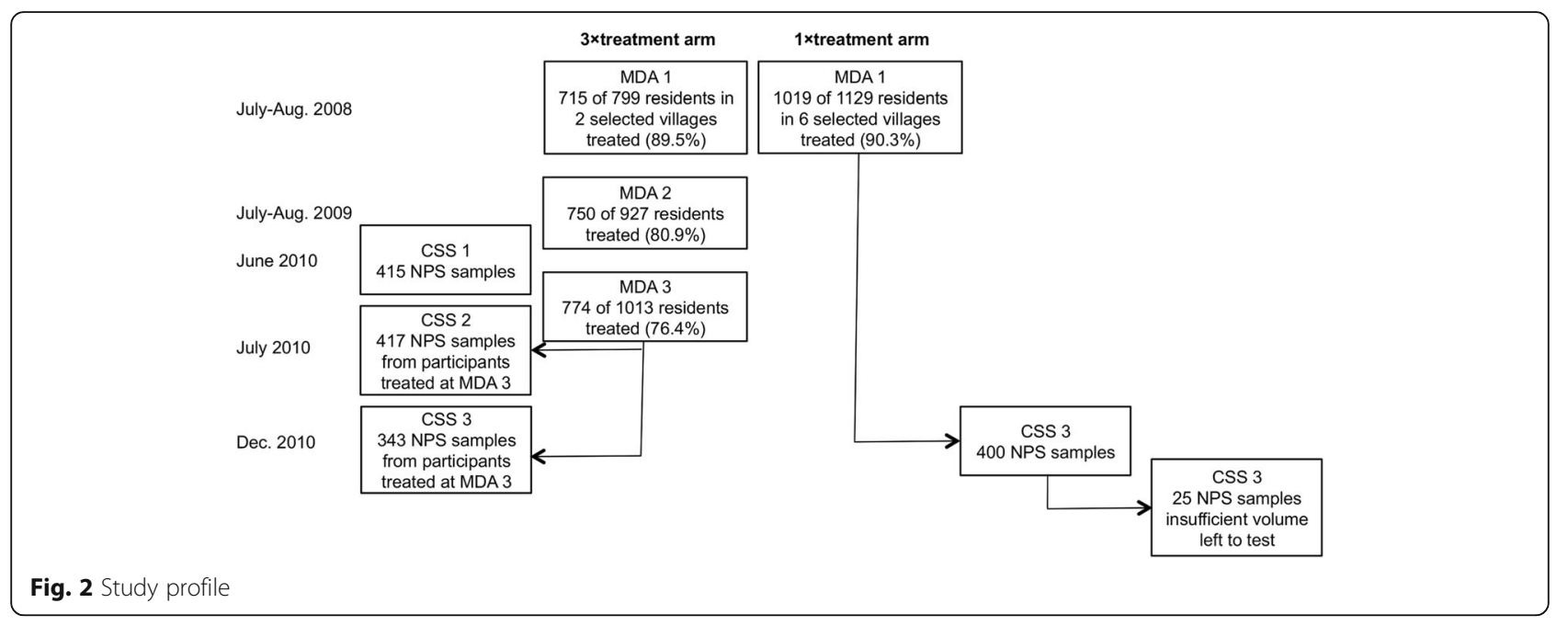

In the $3 \times$ treatment arm, participation in CSS- 2 and 3 was restricted to those who were documented to have received azithromycin during the third round of MDA in July 2010. At each CSS, a nasopharyngeal swab (NPS) was collected from each participant and a questionnaire, pertaining to demographic characteristics, socioeconomic status and recent antibiotic use (within the last 30 days), was conducted. In the present study, we analysed all NPS samples collected as a part of the pneumococcal carriage study [12] to determine the prevalence of S. aureus carriage, including carriage of macrolide resistant strains.

\section{Specimen collection}

NPS samples were collected using calcium alginate swabs and inoculated into sterile vials containing skimmilk-tryptone-glucose glycerol transport medium, which has been shown to preserve the viability of respiratory pathogens for up to 12 years when stored at $-70{ }^{\circ} \mathrm{C}$ [28]. Samples were kept on wet-ice in the field, transferred to a $4{ }^{\circ} \mathrm{C}$ refrigerator within $8 \mathrm{~h}$ of collection and moved to long-term storage at $-80{ }^{\circ} \mathrm{C}$ within $24 \mathrm{~h}$ of collection. Samples remained in long-term storage at $-80{ }^{\circ} \mathrm{C}$ with back-up power and twice daily temperature monitoring for 18 months before being cultured for $S$. aureus.

\section{Laboratory methods}

NPS samples were thawed at room temperature and $10 \mu \mathrm{l}$ transport medium was inoculated onto Mannitol Salt Agar (Oxoid Ltd, Basingstoke, UK) and incubated for 18$24 \mathrm{~h}$ at $35^{\circ} \mathrm{C}$. Presumptive $S$. aureus colonies were subcultured for purity on a Blood Agar Base No. 2 (Oxoid Ltd, Basingstoke, UK) supplemented with 5\% sheep blood (TCS Biosciences Ltd., Botolph Clayton, UK) and incubated under the same conditions. A coagulase agglutination test was performed on well-isolated colonies to confirm the identification of S. aureus using the SLIDEX Staph-kit (Biomerieux UK Limited, Basingstoke, UK).
Well-isolated S. aureus colonies were suspended in nutrient broth (Oxoid Ltd, Basingstoke, UK) to a 0.5 McFarland standard and plated on Mueller-Hinton Agar (Oxoid Ltd, Basingstoke, UK). Azithromycin (15 $\mu \mathrm{g})$, erythromycin $(15 \mu \mathrm{g})$ and clindamycin $(2 \mu \mathrm{g})$ discs (Oxoid Ltd, Basingstoke, UK) were placed aseptically on each plate with the erythromycin and clindamycin discs spaced $15 \mathrm{~mm}$ apart from edge-to-edge. The plates were incubated for $18-24 \mathrm{~h}$ at $35^{\circ} \mathrm{C}$.

Sensitivity results were interpreted according to the Clinical and Laboratory Standards Institute guidelines [29]. Azithromycin resistance $\left(\mathrm{Azm}^{\mathrm{R}}\right)$ was defined by a zone size $\leq 13 \mathrm{~mm}$. Macrolide-inducible-clindamycin resistance, also referred to as the inducible Macrolide-LincosamideStreptogramin B (iMLS $\mathrm{B}_{\mathrm{B}}$ ) phenotype, was defined as flattening of the circular zone of inhibition around the clindamycin disc on the side facing the erythromycin disc (D-test) [30]. Constitutive clindamycin resistance $\left(\mathrm{Cli}^{\mathrm{R}}\right)$ was defined as a circular zone of inhibition $\leq 14 \mathrm{~mm}$.

Twenty-three $S$. aureus isolates obtained from the $3 \times$ treatment arm at CSS-1 and CSS-2 were randomly selected for analysis of the presence of 117 of the most prevalent and transferable antibiotic resistance determinants found in Gram-positive bacteria using micro-array, as previously described [31].

Laboratory technicians were blind to the treatment arm and the timing of sample collection.

\section{Data management and statistical analysis}

Data were double-entered into an OpenClinica database and the validated data imported into Stata version 12 (StataCorp LP, College Station, Texas, USA) for statistical analyses. Proportions of overall carriage and carriage of antimicrobial resistant $S$. aureus were compared using ChiSquare or Fisher's exact tests. Logistic regression analyses were further used to identify risk factors for carriage, control for confounders and test for interactions, reporting 
odds ratios with $95 \%$ confidence intervals (CI). CIs and pvalues were estimated using clustered robust standard errors to account for within village correlation of participants. Analysis included overall prevalence of nasopharyngeal carriage, prevalence of carriage of $\mathrm{Azm}^{\mathrm{R}}$ and $\mathrm{iMLS}_{\mathrm{B}}$ strains and proportions of $\mathrm{Azm}^{\mathrm{R}}$ and $\mathrm{iMLS} \mathrm{B}_{\mathrm{B}}$ strains isolated.

\section{Ethical review}

This study was ancillary to the PRET trial and was approved by The Gambia Government/Medical Research Council Unit, The Gambia Joint Ethics Committee. Written, informed consent was obtained from all participants of the PRET trial and additional written consent was obtained for this ancillary study. In the case of minors, informed consent was obtained from the parent or guardian.

\section{Results}

\section{Study participants}

In the $3 \times$ treatment arm, NPS were collected from 415 , 417 and 343 individuals at CSS-1, CSS-2 and CSS-3, respectively. Four hundred participants in the $1 \times$ treatment arm were also sampled at CSS-3. Overall, 25 NPS from the $1 \times$ treatment arm (6.2\% of 400 samples) had insufficient volume remaining to conduct the laboratory assays and were excluded from the analysis. Demographic and epidemiological characteristics of the participants, including S. pneumoniae carriage [12], are given in Table 1.

\section{Prevalence of S. aureus carriage}

Prevalence of nasopharyngeal $S$. aureus carriage at CSS-1 was $24.6 \%$ (102/414 participants) (Table 2). One month following MDA, prevalence of carriage in the same study villages increased to $38.6 \%(161 / 417 ; p<0.001)$ then fell to $8.8 \%$ at CSS-3, 6 months following MDA (30/343; $p<$ 0.001 ) (Table 2). In the $1 \times$ treatment arm, prevalence of $S$. aureus at CSS- 3 was similar to the $3 \times$ treatment arm $(6.7 \%$ versus $8.8 \%, p<0.295)$ (Table 2 ).

\section{Prevalence of antibiotic resistant $S$. aureus}

In the $3 \times$ treatment arm, prevalence of carriage of azithromycin resistant $\left(\mathrm{Azm}^{\mathrm{R}}\right)$ strains at CSS-1 was 8.9\% (37/414) (Table 3). This rose significantly to $34.1 \%$ at CSS-2, 1 month

Table 1 Demographic characteristics of study participants at each cross-sectional survey

\begin{tabular}{|c|c|c|c|c|}
\hline & \multicolumn{4}{|l|}{ Survey $^{a}$} \\
\hline & CCS-1 & CCS-2 & CCS-3 & CCS-3 \\
\hline \multicolumn{5}{|l|}{ Arm } \\
\hline $1 \times$ treatment & - & - & $375(100.0 \%)$ & $0(0.0 \%)$ \\
\hline $3 \times$ treatment & $414(100.0 \%)$ & $417(100.0 \%)$ & $0(0.0 \%)$ & $343(100.0 \%)$ \\
\hline \multicolumn{5}{|l|}{ Age group } \\
\hline$<10 y$ & $205(49.5 \%)$ & $173(41.5 \%)$ & 157 (41.9\%) & $182(53.1 \%)$ \\
\hline$\geq 10 y$ & 209 (50.5\%) & $244(58.5 \%)$ & $218(58.1 \%)$ & $161(46.9 \%)$ \\
\hline Gender (males) & $218(52.7 \%)$ & $209(50.1 \%)$ & 198 (52.8\%) & $158(46.1 \%)$ \\
\hline Ethnicity (Jola) & $408(98.6 \%)$ & 407 (97.6\%) & $346(92.3 \%)$ & $333(97.1 \%)$ \\
\hline \multicolumn{5}{|l|}{ Occupation } \\
\hline None & $185(45.2 \%)$ & $162(39.0 \%)$ & 135 (38.1\%) & 169 (50.0\%) \\
\hline Student & $148(36.2 \%)$ & 149 (35.9\%) & $128(36.2 \%)$ & $90(26.6 \%)$ \\
\hline Agriculture & $76(18.6 \%)$ & $104(25.1 \%)$ & $91(25.7 \%)$ & 79 (23.4\%) \\
\hline \multicolumn{5}{|l|}{ Schooling years } \\
\hline 0 & $260(62.8 \%)$ & $258(61.9 \%)$ & $240(64.0 \%)$ & $242(71.8 \%)$ \\
\hline$(1-3)$ & $72(17.4 \%)$ & $67(16.1 \%)$ & $58(15.5 \%)$ & $36(10.7 \%)$ \\
\hline$(4-6)$ & $51(12.3 \%)$ & $48(11.5 \%)$ & $11(2.9 \%)$ & $25(7.4 \%)$ \\
\hline$>6$ & $31(7.5 \%)$ & $44(10.6 \%)$ & $66(17.6 \%)$ & $34(10.1 \%)$ \\
\hline Able to read (yes) & $155(37.4 \%)$ & $158(37.9 \%)$ & $76(20.3 \%)$ & $56(16.3 \%)$ \\
\hline Able to write (yes) & $154(37.2 \%)$ & $158(37.9 \%)$ & $92(24.5 \%)$ & $63(18.4 \%)$ \\
\hline Recent $^{\mathrm{b}}$ health centre visit (yes) & $14(3.4 \%)$ & $12(2.9 \%)$ & $18(4.8 \%)$ & $30(8.8 \%)$ \\
\hline Recent $^{\mathrm{b}}$ antibiotic use (yes) & $2(0.5 \%)$ & $2(0.5 \%)$ & $6(1.6 \%)$ & $4(1.2 \%)$ \\
\hline Smoker in the household (yes) & $264(63.8 \%)$ & $273(65.5 \%)$ & $113(30.2 \%)$ & $166(48.7 \%)$ \\
\hline S. pneumoniae carriage (yes) & $180(43.5 \%)$ & 80 (19.2\%) & 182 (48.5\%) & $157(45.8 \%)$ \\
\hline
\end{tabular}

a Surveys were conducted immediately before the third round of MDA (CSS-1) and at one (CSS-2) and six (CSS-3) months after MDA 
Table 2 Prevalence of S. aureus carriage over time and between treatment arms

\begin{tabular}{|c|c|c|c|c|c|c|c|}
\hline Arm & Survey & $\mathrm{N}$ & n (\%) & Crude OR $(95 \% \mathrm{CI})$ & $p$-value & Adjusted OR $(95 \% \mathrm{Cl})$ & $p$-value \\
\hline \multicolumn{8}{|c|}{ Over time } \\
\hline $3 x$ & CSS-1 & 414 & $102(24.6)$ & 1 & & 1 & \\
\hline $3 x$ & CSS-2 & 417 & $161(38.6)$ & $1.92(1.66-2.23)$ & $<0.001$ & $1.94(1.68-2.24)$ & $<0.001$ \\
\hline $3 x$ & CSS-3 & 343 & $30(8.8)$ & $0.29(0.24-0.36)$ & $<0.001$ & $0.30(0.25-0.35)$ & $<0.001$ \\
\hline \multicolumn{8}{|c|}{ Between treatment arms } \\
\hline $1 \times$ & CSS-3 & 375 & $25(6.7)$ & 1 & & 1 & \\
\hline $3 x$ & CSS-3 & 343 & $30(8.8)$ & $1.34(0.66-2.74)$ & 0.419 & $1.47(0.72-3.00)$ & 0.286 \\
\hline
\end{tabular}

adjusted for age and gender

post MDA, $(142 / 417 ; p<0.001)$ then fell back to previous levels $(7.3 \%, 30 / 343)$ at CSS-3, 6 months post MDA ( $p=$ 0.471 , in comparison to CSS-1). There was no evidence of constitutive clindamycin resistance (constitutive MacrolideLincosamide-Streptogramin B or $\mathrm{CMLS}_{\mathrm{B}}$ phenotype) in the $3 \times$ treatment arm at either CSS-1 or CSS-2. A single $\mathrm{Cli}^{\mathrm{R}}$ isolate was found at CSS-3. Prevalence of carriage of $\mathrm{iMLS}_{\mathrm{B}}$ S. aureus was $5.8 \%(24 / 414)$ at CSS-1 (Table 3), increased to $30.7 \%(128 / 417)$ at CSS-2 $(p<0.001)$ and fell back to previous levels $(5.8 \%, 20 / 343)$ at CSS-3 $(p=0.673)$ (Table 3$)$.

At CSS-3, prevalence of carriage of $\mathrm{Azm}^{\mathrm{R}}$ and $\mathrm{iMLS} \mathrm{S}_{\mathrm{B}}$ $S$. aureus strains in the $3 \times$ treatment arm was significantly higher than that in the $1 \times$ treatment arm $(7.3 \%$ versus $1.6 \% \mathrm{Azm}^{\mathrm{R}}, p=0.010 ; 5.8 \%$ versus $0.8 \% \mathrm{iMLS}_{\mathrm{B}}, p$ $<0.005$ ) (Table 3).

\section{Proportion of antibiotic resistant S. aureus isolates}

When analysed in terms of the proportion of isolates displaying Azm ${ }^{\mathrm{R}}$, the results indicate 36.3\% (37/102) of $S$. aureus isolates were resistant at CSS-1. This increased to $88.2 \%(142 / 161 ; p<0.001)$ at CSS-2 and remained high at CSS-3 with $83.3 \%$ of isolates (25/30) displaying resistance $(p=0.047)$ (Table 3). The proportion of $S$. aureus isolates displaying the $\mathrm{iMLS}_{\mathrm{B}}$ phenotype was $23.5 \%$ (24/102), $79.5 \%(128 / 161)$ and $66.7 \%(20 / 30)$ at CSS-1, CSS-2 and CSS-3 respectively (Table 4 ), suggesting a significant increase following treatment $(p<0.001)$.

Arm comparison at CSS-3 indicated a significantly higher proportion of $\mathrm{Azm}^{\mathrm{R}}$ (83.3\% versus 24.0\%, $p=0.009$ ) and iMLS $_{\mathrm{B}}(66.7 \%$ versus $12.0 \%, p<0.001) \mathrm{S}$. aureus strains in the $3 \times$ treatment arm (Table 4 ).

Table 3 Prevalence of azithromycin-resistant $\left(\mathrm{Azm}^{\mathrm{R}}\right)$ and macrolide-inducible clindamycin resistant (iMLS $\mathrm{B}_{\mathrm{B}}$ ) S. aureus isolates over time and between treatment arms

\begin{tabular}{|c|c|c|c|c|c|c|}
\hline Survey & Total & Resistant (\%) & Crude OR (95\% CI) & $p$-value & Adjusted $\mathrm{OR}^{\mathrm{a}}(95 \% \mathrm{Cl})$ & $p$-value \\
\hline \multicolumn{7}{|l|}{ Overtime } \\
\hline \multicolumn{7}{|l|}{$A z m^{R}$} \\
\hline CSS-1 & 414 & $37(8.9)$ & 1 & & 1 & \\
\hline CSS-2 & 417 & $142(34.1)$ & $5.26(4.95-5.59)$ & $<0.001$ & $5.28(4.95-5.64)$ & $<0.001$ \\
\hline CSS-3 & 343 & $25(7.3)$ & $0.80(0.45-1.42)$ & 0.447 & $0.82(0.47-1.42)$ & 0.471 \\
\hline \multicolumn{7}{|l|}{$\mathrm{iMLS} \mathrm{S}_{B}$} \\
\hline CSS-1 & 414 & $24(5.8)$ & 1 & & 1 & \\
\hline CSS-2 & 417 & $128(30.7)$ & $7.20(3.77-13.76)$ & $<0.001$ & $7.24(3.72-14.1)$ & $<0.001$ \\
\hline CSS-3 & 343 & $20(5.8)$ & $1.01(0.87-1.16)$ & 0.933 & $1.03(0.90-1.17)$ & 0.673 \\
\hline \multicolumn{7}{|c|}{ Between treatment arms } \\
\hline \multicolumn{7}{|l|}{$\mathrm{Azm}^{\mathrm{R}}$} \\
\hline $1 \times$ & 375 & $6(1.6)$ & 1 & & 1 & \\
\hline $3 \times$ & 434 & $25(7.3)$ & $4.83(1.46-16.06)$ & 0.010 & $5.22(1.49-18.34)$ & 0.010 \\
\hline \multicolumn{7}{|l|}{$\mathrm{iMLS} \mathrm{S}_{\mathrm{B}}$} \\
\hline $1 \times$ & 375 & $3(0.8)$ & 1 & & 1 & \\
\hline $3 x$ & 434 & $20(5.8)$ & $7.68(1.80-32.84)$ & 0.006 & $8.37(1.89-37.14)$ & 0.005 \\
\hline
\end{tabular}

adjusted for age and gender 


\section{Antibiotic resistance determinants}

In a subset of $S$. aureus isolates $(N=23)$, the presence of antibiotic resistance determinants was assayed using a DNA microarray [31]. Results are shown in Table 5. No macrolide resistant determinants were found in six isolates that were sensitive to both azithromycin and clindamycin. Of five isolates displaying resistance to azithromycin but sensitivity to clindamycin, all were positive for the $m s r$ gene, which conveys resistance to macrolides and streptogramin B. Twelve isolates were azithromycin resistant and had the $\mathrm{iMLS}_{\mathrm{B}}$ phenotype and all of these carried erm genes $[11 \operatorname{erm}(\mathrm{C})$ and $1 \operatorname{erm}(\mathrm{T})]$, confirming their resistance to the $M L S_{B}$ antibiotics.

Other antimicrobial resistance determinants identified included the beta-lactamase gene blaZ in 21 of isolates screened (91\%), the trimethoprim resistance gene $d f r(G)$ in 7 isolates (30\%) and tetracycline resistance genes in 2 isolates $(9 \%)[1 \operatorname{tet}(\mathrm{M})$ and $2 \operatorname{tet}(\mathrm{K})]$. The norA gene, which confers resistance to norfloxacin if overexpressed, was detected in all 23 isolates (100\%). The Panton-Valentine leukocidin gene, luk-PV, was found in $10(43 \%)$ of the isolates screened.

\section{Risk factors for S. aureus carriage following MDA}

One month following MDA in the $3 \times$ treatment arm, pneumococcal carriage $(\mathrm{OR}=0.58,95 \% \mathrm{CI} 0.46-0.72, p$ $<0.001)$, a recent visit to a health centre $(\mathrm{OR}=0.48,95 \%$ CI $0.45-0.52, p<0.001)$, an occupation in agriculture $(\mathrm{OR}=0.2,95 \% \mathrm{CI} 0.1-0.38, p<0.001)$ and female gender $(\mathrm{OR}=0.75,95 \%$ CI $0.57-1.0, p=0.050)$ were inversely associated with S. aureus carriage at CSS-2 according to the adjusted analysis (Table 6).

\section{Discussion}

In order to explore the effect of repeated MDA with azithromycin on the prevalence of carriage of macrolideresistant S. aureus and the proportion of resistant strains, we compared communities receiving one or three annual treatment rounds. Our results indicate that MDA was associated with a significant increase in the prevalence of carriage of $\mathrm{Azm}^{\mathrm{R}}$ and $\mathrm{iMLS} \mathrm{S}_{\mathrm{B}}$ S. aureus strains immediately following treatment, which returned to lower levels 6 months later. When comparing treatment arms at CSS3 , the prevalence of carriage of resistant $S$. aureus and proportion of resistant strains were higher in those communities that received three rounds of MDA as compared to a single treatment round.

The observation that the prevalence of resistant strains, in the $3 \times$ treatment arm, decreased between CSS-2 and CSS-3 is consistent with research of macrolide resistant Streptococcus pneumoniae following azithromycin MDA that has demonstrated resistant phenotypes have decreased fitness when antibiotic pressure is relieved [32, 33]. It may be that, had we collected additional samples at longer time points following treatment, the prevalence in the $3 \times$ treatment arm may have eventually reached that seen in villages that received only a single round of treatment.

When we examine our results as the proportion of $S$. aureus isolates that display macrolide resistance, rather than the prevalence of carriage of resistant strains,

Table 4 Proportion of azithromycin-resistant $\left(\mathrm{Azm}^{\mathrm{R}}\right.$ ) and macrolide-inducible clindamycin resistant (iMLS $\mathrm{B}_{\mathrm{B}}$ S. aureus isolates over time and between treatment arms

\begin{tabular}{|c|c|c|c|c|c|c|}
\hline Survey & Total & Resistant (\%) & Crude OR (95\% Cl) & $p$-value & Adjusted $\mathrm{OR}^{\mathrm{a}}(95 \% \mathrm{Cl})$ & $p$-value \\
\hline \multicolumn{7}{|l|}{ Overtime } \\
\hline \multicolumn{7}{|l|}{$A z m^{R}$} \\
\hline CSS-1 & 102 & $37(36.3)$ & 1 & & 1 & \\
\hline CSS-2 & 161 & $142(88.2)$ & $13.13(7.67-22.48)$ & $<0.001$ & $13.01(7.77-21.80)$ & $<0.001$ \\
\hline CSS-3 & 30 & $25(83.3)$ & $8.78(1.11-69.25)$ & 0.039 & $8.56(1.03-71.34)$ & 0.047 \\
\hline \multicolumn{7}{|l|}{$\mathrm{iMLS} \mathrm{S}_{\mathrm{B}}$} \\
\hline CSS-1 & 102 & $24(23.5)$ & 1 & & 1 & \\
\hline CSS-2 & 161 & $128(79.5)$ & 12.61 (8.33-19.09) & $<0.001$ & $12.52(7.90-19.85)$ & $<0.001$ \\
\hline CSS-3 & 30 & $20(66.7)$ & $6.50(3.14-13.44)$ & $<0.001$ & $6.39(3.22-12.66)$ & $<0.001$ \\
\hline \multicolumn{7}{|c|}{ Between treatment arms } \\
\hline \multicolumn{7}{|l|}{$\mathrm{Azm}^{\mathrm{R}}$} \\
\hline $1 \times$ & 25 & $6(24.0)$ & 1 & & 1 & \\
\hline $3 \times$ & 30 & $25(83.3)$ & $15.83(1.97-127.01)$ & 0.009 & 15.88 (1.99-126.54) & 0.009 \\
\hline \multicolumn{7}{|l|}{$\mathrm{iMLS} \mathrm{S}_{\mathrm{B}}$} \\
\hline $1 \times$ & 25 & $3(12.0)$ & 1 & & 1 & \\
\hline $3 x$ & 30 & $20(66.7)$ & $14.67(2.43-88.41)$ & 0.003 & $18.83(3.22-110.05)$ & 0.001 \\
\hline
\end{tabular}

adjusted for age and gender 
Table 5 Antimicrobial resistance determinants detected in a random sample of S. aureus isolates, given by phenotype

\begin{tabular}{|c|c|c|c|c|c|c|c|c|c|c|}
\hline \multirow[t]{2}{*}{ Phenotype } & \multirow[t]{2}{*}{ Total } & \multicolumn{8}{|c|}{ Resistance gene(s) detected } & \multirow[t]{2}{*}{ luk-PV } \\
\hline & & $m s r$ & $\operatorname{erm}(C)$ & $\operatorname{erm}(\mathrm{T})$ & $\operatorname{tet}(\mathrm{M})$ & $\operatorname{tet}(\mathrm{K})$ & $d f r(G)$ & norA & blaz & \\
\hline $\mathrm{Azi}^{\mathrm{R}}, \mathrm{iMLS} \mathrm{S}_{\mathrm{B}}$ & 12 & & 11 & 1 & & 1 & 2 & 12 & 10 & 4 \\
\hline $\mathrm{Azi}^{\mathrm{R}}, \mathrm{Cli}^{\mathrm{S}}$ & 5 & 5 & & & & & 2 & 5 & 5 & 2 \\
\hline$A z i^{S}, \mathrm{Cli}^{\mathrm{S}}$ & 6 & & & & 1 & 1 & 3 & 6 & 6 & 4 \\
\hline
\end{tabular}

resistance remains high 6 months following the last round of MDA (83.3\%) suggesting it takes longer for resistance to wane. However, it is difficult to interpret these results as the overall prevalence of $S$. aureus carriage, in both study arms, at CSS-3 was unexpectedly low. While the absolute numbers of resistant isolates were small, so too were the total number of people found to carry $S$. aureus at that time point. Seasonality may explain, at least in part, the difference in carriage between CSS-2 and CSS-3; increased prevalence of $S$. aureus carriage has been reported in a number of populations during the hot, humid summer months [34, 35] and this is consistent with the timing of our surveys (CSS-1 and CSS2 were conducted in the wet season while CSS-3 was conducted in the dry season). However, other external factors may also have played a role. For example, conducting surveys in the wet season while crops are being planted may result in under representation of able-bodied adults amongst those surveyed.

As the proportion of isolates displaying antimicrobial resistance was high, we chose to validate our findings on a subset of isolates using a microarray designed to detect antimicrobial resistance determinants common to Grampositive bacteria [31]. The results confirmed the presence of determinants encoding resistance to macrolide, lincosamide and streptogramin B antibiotics. While macrolides are not first-line therapy for S. aureus infection in Gambia (treatment would usually be cloxacillin or chlorampheni$\mathrm{col})$, their use is indicated in respiratory disease in the case of penicillin allergy and recurrent skin infection, also in the case of penicillin allergy [36]. They would also be considered in the case of suspected atypical pneumonia. The presence of macrolide resistance therefore, while not a cause for immediate concern, is worth monitoring, especially as $91 \%$ of the isolates examined by microarray also carried the blaZ gene, suggesting concurrent resistance to penicillins in the population.

The majority of the resistance to macrolides was attributed to the presence of either $m s r$ or $\operatorname{erm}(\mathrm{C})$ genes however, one strain contained an $\operatorname{erm}(\mathrm{T})$ gene. To date, $\operatorname{erm}(\mathrm{T})$ has been primarily reported in Streptococcus species [37-39] and has rarely been identified in S. aureus isolates $[40,41]$ suggesting it may have been acquired under selective pressure. The trimethoprim resistance gene $d f r(G)$, which was detected in one third of our isolates is reported to be widespread among $S$. aureus isolates in Africa [42]. Almost half of the isolates that were tested by microarray carried the gene encoding Panton-Valentine leukocidin, a pore-forming cytotoxin that has been associated with skin and soft tissue infections and with community-acquired, necrotising haemorrhagic pneumonia $[43,44]$.

$S$. pneumoniae colonization in the nasopharynx is thought, by many, to be negatively associated with $S$. aureus colonization and interventions to reduce pneumococcal carriage have been associated with an increase in $S$. aureus carriage and disease in some populations $[45,46]$. Plausible molecular mechanisms driving competition between the two bacteria are the pneumococcal pilus, which may allow better adherence of S. pneumoniae [47] and hydrogen peroxidase production by $S$. pneumoniae, which inhibits $S$. aureus growth [48]. In our study, $S$. aureus carriage was inversely associated with pneumococcal carriage at CSS2, 1 month following MDA. One possible explanation for this is that the decrease in S. pneumoniae carriage immediately following MDA (Table 1) provided S. aureus the opportunity to expand its presence in the nasopharyngeal niche.

This was an opportunistic study that utilised the framework of the PRET trial $[25,26]$ and the pneumococcal carriage study that was nested within PRET [12] to explore associations between carriage of macrolideresistant $S$. aureus and azithromycin MDA. As such, it has a number of limitations that could have been avoided had this been a prospective study of $S$. aureus carriage. One of these is the lack of baseline data, collected before any MDA. In communities that received just a single round of MDA ( $1 \times$ treatment arm), $24 \%$ of strains isolated were resistant to azithromycin 30 months following treatment (at CSS-3). Data on carriage of macrolide resistant $S$. aureus in The Gambia are scarce, however, samples collected in 2003-2004 from the same region of country as our study (Western Division, now named Brikama Local Government Area) showed 64\% erythromycin susceptibility $[49,50]$. This suggests macrolide resistance was no higher in our $1 \times$ treatment arm at CSS- 3 that it was in the region prior to azithromycin MDA. A survey of school-going children in Cameroon has also reported $75 \%$ susceptibility to erythromycin [51] suggesting our results are similar to levels of resistance in other West African countries. 
Table 6 Risk factors for S. aureus carriage at CSS-2

\begin{tabular}{|c|c|c|c|c|c|c|}
\hline Characteristic & $\mathrm{N}$ & n (\%) & Crude OR (95\% CI) & p-value & Adjusted $\mathrm{OR}^{\mathrm{a}}(95 \% \mathrm{Cl})$ & $p$-value \\
\hline \multicolumn{7}{|c|}{ Pneumococcal carriage } \\
\hline No & 337 & $135(40.1)$ & 1 & & 1 & \\
\hline Yes & 80 & $26(32.5)$ & $0.72(0.67-0.77)$ & $<0.001$ & $0.58(0.46-0.72)$ & $<0.001$ \\
\hline \multicolumn{7}{|l|}{ Age group } \\
\hline$<10 y$ & 173 & $72(41.6)$ & & & & \\
\hline$\geq 10 y$ & 244 & 89 (36.5) & $0.81(0.54-1.2)$ & 0.289 & $1.24(0.74-2.07)$ & 0.418 \\
\hline \multicolumn{7}{|l|}{ Gender } \\
\hline Male & 209 & $90(43.1)$ & 1 & & 1 & \\
\hline Female & 208 & $71(34.1)$ & $0.69(0.47-0.99)$ & 0.044 & $0.75(0.57-1.0)$ & 0.050 \\
\hline \multicolumn{7}{|l|}{ Occupation } \\
\hline None & 162 & $67(41.4)$ & 1 & & 1 & \\
\hline Student & 149 & $77(51.7)$ & $1.52(1.32-1.74)$ & $<0.001$ & $1.12(0.73-1.71)$ & 0.613 \\
\hline Agriculture & 104 & $17(16.4)$ & $0.28(0.10-0.80)$ & 0.017 & $0.2(0.1-0.38)$ & $<0.001$ \\
\hline \multicolumn{7}{|c|}{ Schooling (years) } \\
\hline 0 & 258 & $82(31.8)$ & 1 & & & \\
\hline $1-3$ & 67 & $36(53.7)$ & $2.49(1.62-3.84)$ & $<0.001$ & & \\
\hline $4-6$ & 48 & $23(47.9)$ & $1.97(0.65-6.02)$ & 0.232 & & \\
\hline$>6$ & 44 & $20(45.5)$ & $1.79(1.51-2.12)$ & $<0.001$ & & \\
\hline \multicolumn{7}{|l|}{ Ability to read } \\
\hline No & 259 & $83(32.1)$ & 1 & & & \\
\hline Yes & 158 & $78(49.3)$ & $2.07(1.20-3.56)$ & 0.009 & & \\
\hline \multicolumn{7}{|l|}{ Ability to write } \\
\hline No & 259 & $83(32.1)$ & 1 & & & \\
\hline Yes & 158 & $78(49.4)$ & $2.07(1.20-3.56)$ & 0.009 & & \\
\hline \multicolumn{7}{|c|}{ Recent $^{\mathrm{b}}$ health visit } \\
\hline No & 405 & 159 (39.3) & 1 & & 1 & \\
\hline Yes & 12 & $2(16.7)$ & $0.31(0.22-0.43)$ & $<0.001$ & $0.48(0.45-0.52)$ & $<0.001$ \\
\hline \multicolumn{7}{|c|}{ Recent $^{\mathrm{b}}$ antibiotic use } \\
\hline No & 415 & $160(38.6)$ & 1 & & & \\
\hline Yes & 2 & $1(50.0)$ & $1.59(0.04-59.03)$ & 0.800 & & \\
\hline \multicolumn{7}{|l|}{ Ethnicity (Jola) } \\
\hline No & 10 & $3(30)$ & 1 & & 1 & \\
\hline Yes & 407 & $158(38.8)$ & $1.48(1.04-2.10)$ & 0.028 & $1.5(1.09-2.08)$ & 0.014 \\
\hline \multicolumn{7}{|l|}{ Active smoker } \\
\hline No & 405 & $159(39.3)$ & 1 & & & \\
\hline Yes & 12 & $2(16.7)$ & $0.31(0.03-3.14)$ & & & \\
\hline \multicolumn{7}{|c|}{ Smoker in household } \\
\hline No & 144 & $51(35.4)$ & 1 & & & \\
\hline Yes & 273 & $110(40.3)$ & $1.23(0.63-2.42)$ & 0.548 & & \\
\hline
\end{tabular}

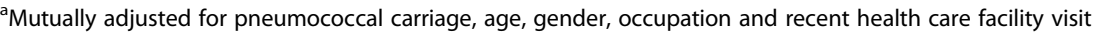
${ }^{b}$ Within the last 30 days

Another limitation was the use of nasopharyngeal swabs, rather than oropharyngeal or nasal swabs, which may have yielded higher numbers of $S$. aureus. However, there is no evidence to suggest the dynamics of macrolide resistance would differ between these respiratory sites. Sampling at additional time points post-MDA would also 
have helped us determine for how long the prevalence and proportion of resistant strains is maintained within communities following three rounds of treatment.

\section{Conclusions}

Three rounds of MDA for trachoma control were associated an increase in the prevalence of carriage of $\mathrm{Azm}^{\mathrm{R}}$ and $\mathrm{iMLS}_{\mathrm{B}} S$. aureus and in the proportion of isolated strains that were resistant to these antibiotics. While the increase in prevalence of carriage of resistant strains was transient, the increase in proportion of resistant strains was maintained for at least 6 months following the final round of MDA. Both the prevalence and the proportion of resistant strains was higher in the $3 \times$ treatment arm than in the $1 \times$ treatment arm. These findings highlight the need for continued antimicrobial resistance monitoring in communities receiving azithromycin treatment at the community-level.

\section{Abbreviations}

Azi $i^{R}$ : Azithromycin resistance; Cl: Confidence interval; $\mathrm{Cli}^{\mathrm{R}}$ : Clindamycin resistance; $\mathrm{CMLS}_{\mathrm{B}}$ : Constitutive Macrolide-Lincosamide-Streptogramin B phenotype; CSS: Cross sectional survey; $\mathrm{MLLS}_{\mathrm{B}}$ : Inducible Macrolide-Lincosamide-Streptogramin B phenotype; MDA: Mass drug administration; NPS: Nasopharyngeal swab; PRET: Partnership for the Rapid Elimination of Trachoma

\section{Acknowledgements}

We would like to thank the following individuals for their efforts in the field: Omar Jarra, Lamin Camara, Musukoi Jammeh, Megha Rajasekhar, Hassan Joof, Pateh Makalo, Sarjo Dibba, Lamin Leigh, Tumani Kuyateh, Omar Manneh, Omar Camara, and Sidu Sibi. We also thank Alexandra Collaud (Institute of Veterinary Bacteriology, University of Bern) for assistance with the microarray work and the community leaders and villagers for their participation in the study.

\section{Funding}

This work was supported by the Bill and Melinda Gates Foundation (grant number 48027) and by the Wellcome Trust (grant number WT093368MA). The funders had no role in the study design, data collection, analysis and interpretation of the data, decision to publish, or preparation of the manuscript.

\section{Availability of data and materials}

Data supporting the findings is contained within the manuscript.

\section{Authors' contributions}

EB carried out the bacterial culture and antibiotic susceptibility testing and drafted the manuscript, JJ performed the statisitical analysis, VP carried out the microarray work and assisted in writing the manuscript, $\mathrm{JH}$ provided supervision for sample collection, EMH-E provided supervision in the field and assisted in writing the manuscript, AS provided supervision in the field, DCWM obtained funding and assisted in writing the manuscript, MJH obtained funding and assisted in writing the manuscript, RB obtained funding and assisted in writing the manuscript, AR was involved in study design, supervision in the field, interpretation of the data and writing of the manuscript, SEB was involved in study design, supervision in the field and laboratory, interpretation of the data and drafting of the manuscript. All authors read and approved the final manuscript.

\section{Competing interests}

The authors declare that they have no competing interests.

\section{Consent to publish}

Not applicable.

\section{Ethics approval and consent to participate}

This study was approved by The Gambia Government/Medical Research Council Unit, The Gambia Joint Ethics Committee under study numbers L2010.34, L2011.65 and L2013.32. Written, informed consent was obtained from all adult participants. In the case of minors, informed consent was obtained from the parent or guardian.

\section{Publisher's Note}

Springer Nature remains neutral with regard to jurisdictional claims in published maps and institutional affiliations.

\section{Author details}

${ }^{1}$ Disease Control and Elimination Theme, Medical Research Council Unit, The Gambia, Fajara, Banjul, The Gambia. ${ }^{2}$ Institute of Veterinary Bacteriology, Vetsuisse Faculty, University of Bern, $\mathrm{CH}-3012$ Bern, Switzerland. ${ }^{3}$ Department of Clinical Research, London School of Hygiene and Tropical Medicine, London WC1E 7HT, UK. ${ }^{4}$ National Eye Health Programe, Ministry of Health and Social Welfare, Kanifing, The Gambia. ${ }^{5}$ Faculty of Epidemiology and Population Health, London School of Hygiene and Tropical Medicine, London WC1E 7HT, UK.

Received: 6 December 2016 Accepted: 11 March 2017

Published online: 28 March 2017

\section{References}

1. World Health Organization. Report of the first meeting of the WHO alliance for the Global Elimination of Trachoma, WHO/PBL/GET/97.1. 1997. http://www. who.int/pbd/publications/trachoma/en/get_1997.pdf. Accessed 4 Nov 2016.

2. World Health Organization. Report of the third meeting of the WHO Alliance for the Global Elimination of Trachoma, WHO/PBD/GET/99.3. 1998. http://www.who. int/pbd/publications/trachoma/en/get_oct1998.pdf. Accessed 4 Nov 2016.

3. Porco TC, Gebre T, Ayele B, House J, Keenan J, Zhou Z, et al. Effect of mass distribution of azithromycin for trachoma control on overall mortality in Ethiopian children: a randomized trial. JAMA. 2009;302:962-8.

4. Keenan JD, Ayele B, Gebre T, Zerihun M, Zhou Z, House II, et al. Childhood mortality in a cohort treated with mass azithromycin for trachoma. Clin Infect Dis. 2011:52:883-8.

5. Matheson Al, Manhart LE, Pavlincan PB, Means AR, Akullian A, Levine GA, et al. Prioritizing countries for interventions to reduce child mortality: tools for maximizing the impact of mass drug administration of azithromycin. PLoS One. 2014;9:e96658.

6. ClinicalTrials.gov. https://clinicaltrials.gov/ct2/show/NCT02047981?term= MORDOR\&rank=1. Accessed 2 Mar 2015.

7. Solomon AW, Mohammed Z, Massae PA, Shao JF, Foster A, Maclean IW, et al. Impact of mass distribution of azithromycin on the antibiotic susceptibilities of ocular Chlamydia trachomatis. Antimicrob Agents Chemother. 2005;49:4804-6.

8. Hong KC, Schachter J, Moncada J, Zhou Z, House J, Lietman TM. Lack of macrolide resistance in Chlamydia trachomatis after mass azithromycin distributions for trachoma. Emerg Infect Dis. 2009;15:1088-90.

9. West SK, Moncada J, Munoz B, Mkocha H, Storey P, Hardick J, et al. Is there evidence for resistance of ocular Chlamydia trachomatis to azithromycin after mass treatment for trachoma control? J Infect Dis. 2014;210:65-71.

10. Batt SL, Charalambous BM, Solomon AW, Knirsch C, Massae PA, Safari S, et al. Impact of azithromycin administration for trachoma control on the carriage of antibiotic-resistant Streptococcus pneumoniae. Antimicrob Agents Chemother. 2003:47:2765-9.

11. Gaynor BD, Holbrook KA, Whitcher JP, Holm SO, Jha HC, Chaudhary JSP, et al. Community treatment with azithromycin for trachoma is not associated with antibiotic resistance in Streptococcus pneumoniae at 1 year. $\mathrm{Br} \mathrm{J}$ Ophthalmol. 2003;87:174-8.

12. Burr SE, Milne S, Jafali J, Bojang E, Rajasekhar M, Hart J, et al. Mass administration of azithromycin and Streptococcus pneumoniae carriage: cross-sectional surveys in the Gambia. Bull World Health Organ. 2014;92:490-8.

13. Fry AM, Jha HC, Lietman TM, Chaudhary JSP, Bhatta RC, Elliott J, et al. Adverse and beneficial secondary effects of mass treatment with azithromycin to eliminate blindness due to trachoma in Nepal. Clin Infect Dis. 2002;35:395-402.

14. Leach AJ, Shelby-James TM, Mayo M, Gratten M, Laming AC, Currie BJ, et al. A prospective study of the impact of community-based azithromycin treatment of trachoma on carriage and resistance of Streptococcus pneumonia. Clin Infect Dis. 1997;24:356-62. 
15. Coles CL, Mabula K, Seidman JC, Levens J, Mkocha H, Munoz B, et al. Mass distribution of azithromycin for trachoma control is associated with increased risk of azithromycin-resistance S. pneumoniae carriage in young children 6 months after treatment. Clin Infect Dis. 2013;56:1519-26.

16. Skalet AH, Cevallos V, Ayele B, Gebre T, Zhou Z, Jorgensen JH, et al. Antibiotic selection pressure and macrolide resistance in nasopharyngeal Streptococcus pneumoniae: a cluster-randomized clinical trial. PLoS Med. 2010;7:e1000377.

17. Haug S, Lakew T, Habtemariam G, Alemayehu W, Cevallos V, Zhou Z, et al. The decline of pneumococcal resistance after cessation of mass antibiotic distributions for trachoma. Clin Infect Dis. 2010;51:571-4.

18. Waters D, Jawad I, Ahmad A, Lukšić I, Nair H, Zgaga L, et al. Aetiology of community-acquired neonatal sepsis in low and middle-income countries. J Glob Health. 2011;2:154-70.

19. Marshall C, McBryde E. The role of Staphylococcus aureus carriage in the pathogenesis of bloodstream infection. BMC Res Notes. 2014;7:428.

20. Levy PY, Ollivier M, Drancourt M, Raoult D, Argenson JN. Relation between nasal carriage of Staphylococcus aureus and surgical site infection in orthopedic surgery: the role of nasal contamination. A systematic literature review and meta-analysis. Orthop Traumatol Surg Res. 2013;99:645-51.

21. Rojo P, Barrios M, Palacios A, Gomez C, Chaves F. Community-associated Staphylococcus aureus infections in children. Expert Rev Anti Infect Ther. 2010;8:541-5.

22. Uhlemann AC, Otto M, Lowy FD, DeLeo FR. Evolution of community- and healthcare-associated methicillin-resistance Staphylococcus aureus. Infect Genet Evol. 2014:21:563-74.

23. Isendahl J, Manjuba C, Rodrigues A, Xu W, Henriques-Normark B, Giske CG, et al. Prevalence of community-acquired bacteremia in Guinea-Bissau: an observational study. BMC Infect Dis. 2014;14:3859.

24. Falade AG, Lagunju IA, Bakare RA, Odekanmi AA, Adegbola RA. Invasive pneumococcal disease in children aged $<5$ years admitted to 3 urban hospital in Ibadan, Nigeria. Clin Infect Dis. 2009;48 Suppl 2:S190-6.

25. Stare D, Harding-Esch E, Munoz B, Bailey R, Mabey D, Holland MJ, et al. Design and baseline data of a randomized trial to evaluate coverage and frequency of mass treatment with azithromycin: the Partnership for Rapid Elimination of Trachoma (PRET) in Tanzania and The Gambia. Ophthalmic Epidemiol. 2011:18:20-9.

26. Harding-Esch EM, Sillah A, Edwards T, Burr SE, Hart JD, Joof H, et al. Mass treatment with azithromycin for trachoma: When is one round enough? Results from the PRET Trial in The Gambia. PLoS Negl Trop Dis. 2013;7:e2115.

27. Roca A, Hill PC, Townend J, Egere U, Antonio M, Bojang A, et al. Effects of community-wide vaccination with PCV-7 on pneumococcal nasopharyngeal carriage in the Gambia: a cluster-randomized trial. PLoS Med. 2011;8(10):e1001107.

28. Hare KM, Smith-Vaughan HC, Leech AJ. Viability of respiratory pathogens cultured from nasopharyngeal swabs stored for up to 12 years at -70 degrees in skim milk tryptone glucose glycerol broth. J Microbiol Methods. 2011;86:364-7

29. Clinical and Laboratory Standards Institute. Performance standards for antimicrobial susceptibility testing; Twenty third informational supplement. CLSI M100-S23. Wayne: Clinical and Laboratory Standards Institute; 2013.

30. Fiebelkorn KR, Crawford SA, McElmeel ML, Jorgensen JH. Practical disk diffusion method for detection of inducible clindamycin resistance in Staphylococcus aureus and Coagulase-Negative Staphylococci. J Clin Microbiol. 2003:41:4740-4.

31. Strauss C, Endimiani A, Perreten V. A novel universal DNA labeling and amplification system for rapid microarray-based detection of 117 antibiotic resistance genes in Gram-positive bacteria. J Microbiol Methods. 2015;108:25-30.

32. Andersson DI, Hughes D. Antibiotic resistance and its cost: is it possible to reverse resistance? Nat Rev Microbiol. 2010;8:260-71.

33. Maher MC, Alemayehu A, Lakew T, Gaynor BD, Haug S, Cevallos V, et al. The fitness cost of antibiotic resistance in Streptococcus pneumoniae: insight from the field. PLoS One. 2012;7:e29407.

34. Smith TC, Forshey BM, Hanson BM, Wardyn SE, Moritz ED. Molecular and epidemiological predictors of Staphylococcus aureus colonization site in a population with limited nosocomial exposure. Am J Infect Control. 2012;40:992-6.

35. Leekha S, Diekema DJ, Perencevich EN. Seasonality of staphylococcal infections. Clin Microbiol Infect. 2012;18:927-33.

36. The Gambia standard drug treatment guidelines. 2001. http://apps.who.int/ medicinedocs/documents/s22418en/s22418en.pdf. Accessed 27 Mar 2017.

37. DiPersio LP, DiPersio JR, Beach JA, Loudon AM, Fuchs AM. Identification and characterization of plasmid-borne erm(T) macrolide resistance in group $B$ and group A Streptococcus. Diagn Microbiol Infect Dis. 2011;71:217-23.
38. Woodbury RL, Klammer KA, Xiong Y, Bailiff T, Glennen A, Bartkus JM, Active Bacterial Core Surveillance Team, et al. Plasmid-borne erm(T) from invasive, macrolide-resistant Streptococcus pyogenes strains. Antimicrob Agents Chemother. 2008;52:1140-3.

39. Dipersio LP, Dipersio JR. Identification of an erm(T) gene in strains of inducibly clindamycin-resistance group B Streptococcus. Diagn Microbiol Infect Dis. 2007;57:189-93.

40. Uhlemann AC, Porcella SF, Trivedi S, Sullivan SB, Hafer C, Kennedy AD, et al. Identification of a highly transmissible animal-independent Staphylococcus aureus ST398 clone with distinct genomic and cell adhesion properties. MBio. 2012;3:e00027-12

41. Vandendriessche S, Kadlec K, Schwarz S, Denis O. Methicillin-susceptible Staphylococcus aureus ST398-t571 harbouring the macrolide-lincosamidestreptogramin B resistance gene erm(T) in Belgian hospitals. J Antimicrob Chemother. 2011:66:2455-9.

42. Nurjadi D, Olalekan AO, Layer F, Shittu AO, Alabi A, Ghebremedhin B, et al. Emergence of trimethoprim resistance gene $d f r G$ in Staphylococcus aureus causing human infection and colonization in sub-Saharan Africa and its import to Europe. J Antimicrob Chemother. 2014;69:2361-8.

43. Papenburg J, Fontela P, Raynal L, Jetté L, Ismail J, Bekal S, et al. PantonValentine leukocidin in pediatric community-acquired Staphylococcus aureus infections. Clin Invest Med. 2009:32:e352-9.

44. Shallcross LJ, Fragaszy E, Johnson AM, Hayward AC. The role of the PantonValentine leucocidin toxin in staphylococcal disease: a systematic review and meta-analysis. Lancet Infect Dis. 2013;13:43-54.

45. Bogaert D, van Belkum A, Sluijter M, Luijendijk A, de Groot R, Rümke HC, et al. Colonisation by Streptococcus pneumoniae and Staphylococcus aureus in healthy children. Lancet. 2004;363:1871-2.

46. Van Gils EJ, Hak E, Veenhoven RH, Rodenburg GD, Bogaert D, Bruin JP, et al. Effect of seven-valent pneumococcal conjugate vaccine on Staphylococcus aureus colonisation in a randomised controlled trial. PLoS One. 2011;6:e20229.

47. Regev-Yochay G, Lipsitch M, Basset A, Rubinstein E, Dagan R, Raz M, et al. The pneumococcal pilus predicts the absence of Staphylococcus aureus cocolonization in pneumococcal carriers. Clin Infect Dis. 2009;48:760-3.

48. Regev-Yochay G, Trzcinski K, Thompson CM, Malley R, Lipsitch M. Interference between Streptococcus pneumonia and Staphylococcus aureus: In vitro hydrogen peroxide-mediated killing by Streptococcus pneumoniae. J Bacteriol. 2006;188:4996-5001.

49. Hill PC, Akisanya A, Sankareh K, Cheung YB, Saaka M, Lahai G, et al. Nasopharyngeal carriage of Streptococcus pneumoniae in Gambian villagers. Clin Infect Dis. 2006:43:673-9.

50. Ebruke C, Dione MM, Walter B, Worwui A, Adegbola A, Roca A, et al. High genetic diversity of Staphylococcus aureus strains colonising the nasopharynx of Gambian villagers before widespread use of pneumococcal conjugate vaccines. BMC Microbiol. 2016;16:38.

51. Ndip RN, Ntiege EA, Ndip LM, Nkwelang G, Akoachere JF, Akenji TN. Antimicrobial resistance of bacterial agents of the upper respiratory tract of school children in Buea, Cameroon. J Health Popul Nutr. 2008:26:97-404.

\section{Submit your next manuscript to BioMed Central and we will help you at every step:}

- We accept pre-submission inquiries

- Our selector tool helps you to find the most relevant journal

- We provide round the clock customer support

- Convenient online submission

- Thorough peer review

- Inclusion in PubMed and all major indexing services

- Maximum visibility for your research

Submit your manuscript at www.biomedcentral.com/submit
) Biomed Central 